\title{
Analysis of the Behavior of Volatility in Crude Oil Price
}

\author{
Fernando Antonio Lucena Aiube a, Tara Keshar Nanda Baidya ${ }^{*}$ \\ a Petrobras and Departmentof Industrial Engineering - PUC - Rio, Rua Marquês de São Vicente, RJ, Brazil. \\ Email: aiube@puc-rio.br \\ bPrograma de Pós-Graduação em Administração - PPGA Mestrado e Doutorado em Administração and \\ Escola de Ciência e Tecnologia UNIGRANRIO.Email: tarabaidya@yahoo.com.br \\ * Corresponding author.
}

\author{
H I G H L I G H T S: \\ 1. We study the behavior of the volatility in crude oil spot prices series comparing low and high prices regime. \\ 2. We filtered the future term-structure to estimate spot price series. \\ 3. Estimated series has the same stylized properties observed on equities and futures, traded on exchanges. \\ 4. The volatility, estimated with GARCH models, do not differ between low and prices regimes. \\ 5. The persistence during the high prices regime decreased.
}

\begin{tabular}{|c|c|}
\hline Article History ${ }^{\diamond}$ & ABSTRACT \\
\hline $\begin{array}{l}\text { Received: 07-01-2014 } \\
\text { Revision: 10-02-2014 } \\
\text { Accepted: 28-02-2014 } \\
\text { Available online: 28-02-2014 } \\
\text { Keywords: } \\
\text { GARCH models; } \\
\text { Two-factor model; } \\
\text { Crude oil; } \\
\text { Volatility. }\end{array}$ & $\begin{array}{l}\text { This article analyzes volatility in the spot price of crude oil In recent years the price has also } \\
\text { increased reaching more than US\$ } 140 / \text { barrel in the last decade. Moreover, the negotiated } \\
\text { trading volume in the futures market in recent years higher than the trading volume of the } \\
\text { earlier years. How these changes have affected the volatility in the oil prices? Does the } \\
\text { presence of huge players, which leads to an increase in the volume under negotiation, } \\
\text { increase volatility? Has the persistence been affected? To answer these questions, we first } \\
\text { estimated spot prices using the two-factor model of Schwartz and Smith. With this filtering } \\
\text { process we can capture the entire information from the future term-structure. We then } \\
\text { analyzed the estimated spot-price series to identify the stylized facts and then adjusted } \\
\text { conditional volatility models of GARCH family. Our findings show that the volatility in the high } \\
\text { prices period is not different from that of low prices. The shocks behaved as transitory and } \\
\text { the persistence in the high prices period decreased. This fact has pricing and hedging } \\
\text { implications for short-term derivatives. }\end{array}$ \\
\hline
\end{tabular}

JEL Classification: C13; C22; G13; C58. DOI: http://dx.doi.org/10.18533/jefs.v2i01.129

(C) 2014 The Authors. This is an open access article under the terms of the Creative Commons Attribution License 4.0, which allows use, distribution and reproduction in any medium, provided the original work is properly cited.

\subsection{Introduction}

This article analyzes the behavior of volatility in the spot price of crude oil. As the spot price is not directly observed, it is estimated based on prices in the futures market. The futures market for oil has existed since the early 1980s. The most important markets in which the negotiation of crude takes place are NYMEX (New York Mercantile Exchange), where light oil WTI (West Texas Intermediate) is negotiated, and the IPE (International Petroleum Exchange) in London, where Brent crude is negotiated. Currently, the NYMEX market is larger than the IPE in terms of the volume and value negotiated. In NYMEX, futures contracts have maturities that range from 1 month to 7 years.

$\diamond$ The authors are grateful to the participants of the VI Brazilian Finance Conference (2007), the Executive Editor of International Journal of Economics, and also the two anonymous referees for their helpful comments, which have improved the final version. The usual disclaim applies. 
Historical quotations of WTI oil prices are available since January 1985. Of all the contracts that mature after 1 month the lowest price was US\$10.72/bbl on 12/10/1998. In September 2000, the price of crude was US\$37/bbl; in January 2002 the price had dropped under US\$20/bbl, and since then the price has increased steadily, reaching more than US\$140.00/bbl in July 200. From 1998, when prices were at their lowest levels, to nowadays, the volume of contracts has more than doubled. There are many reasons for this high-price scenario, but we are not going to discuss them in the present study. The activities of Hedge Funds, negotiating huge volumes, have certainly affected prices. Barsky and Kilian (2004) analyzed the causes and impacts of oil prices since the 1970s. In the present study, the focus is on volatility. We analyze the behavior of volatility in the spot price of crude oil from January 1990 until the beginning of 2006, seeking to answer the following questions. (1) Is recent volatility different from that when prices varied within significantly lower price ranges? (2) The current market appears to be more speculative, but is it necessarily more volatile? (3) How does the volatility behave during the transition period when prices moved systematically to the recent higher levels? (4) Have the price shocks been essentially transitory or do they exhibit persistence? We studied volatility in oil prices based on GARCH models. The importance of deriving answers to these questions is related to the pricing of oil derivatives. In addition, volatility in oil prices affects other energy markets that are much more integrated than previously. If volatility shocks are highly persistent, then investment decisions must take this fact into consideration. Similarly, high persistence can affect the agents who negotiate contracts with long-term maturity. Hedge strategies are strongly affected by changes in volatility regimes. For example, Baillie and Myers (1991) show that a strategy in which the hedge ratio varies through time is better than the strategy that employs a constant hedge ratio.

There is a large volume of literature that examines the volatility in financial markets. Specifically, we concentrate on articles related to oil and other commodities. Lautier and Riva (2004) investigated whether the existence of a derivative market affects the oil futures market. Horan et al. (2004) analyzed volatility in the futures market by extracting the implied volatility from option contracts for periods coinciding with OPEC meetings. The results show that the implied volatility increases before the meetings and decreases as soon as the deliberations are announced, significantly affecting oil prices. Hadsell et al. (2004) estimated the volatility in the spot price of electricity in the US market. They used the GARCH family to identify the effects of asymmetric shocks and seasonal effects in different regional markets. Wilson et al. (1996) analyzed the behavior of volatility in the oil sector by searching for moments of high impact or breaks in the historical series. They used the cumulative sum of square residuals to detect these changes. This approach represents an alternative to the use of parametric procedures as GARCH models. The authors also used dummies in the ARCH model as indication points for breaks in volatility. Pindyck (2004) analyzed the behavior of volatility in the spot price of natural gas and oil in US markets from 1990 until February 2003. The author searched for significant increases in volatility associated with the movement to high prices after 2000 and investigated whether the collapse of Enron brought about increased volatility to the market.

Our approach is quite similar to that used in Pindyck (2004); however, there are two fundamental differences in our approach. The first is related to the way that the spot price is estimated, while the second is related to the GARCH models used to analyze the data.

We estimated the spot prices with a different methodology. The spot price series on commodities should be viewed with care. In general, spot price series used in the literature does not come from trading on exchanges. The origin of these series is from specialized firms that provide them and much other information to their clients. They collect the price information from traders on the physical market of the commodity. The traders have no commitment on buying or selling the product. Hence, price information comes under many differences from that of exchanges, where the details such as properties of the product, point and date of the settlement are well known by agents who are committed to a deal. The U.S.-EIA (2002) report highlighted this issue. Also, Mu (2007), analysing how the weather affects the natural gas prices, emphasizes this point, based on the same report. This is why in many empirical works the first-month-ahead contract is used as a proxy to the spot price. However it is not actually the spot price. In this study, we estimated the spot prices through a filtering process of future prices. In this manner, the estimated spot price captures the information available from the whole term-structure of future prices. The second difference relies on the use of non-linear GARCH models accounting for asymmetric or leverage effect, a usual property of financial time series.

The remainder of this paper is organized as follows: Section 2 describes the method of estimating spot prices, Section 3 verifies the stylized facts in the estimated spot prices, Section 4 reports on the models of conditional volatility, and Section 5 details the main conclusions of the study.

\section{$2.0 \quad$ Estimation of spot prices}

In general, the spot prices of commodities are not directly observed in the market; accordingly, they must be estimated based on observations of the futures market where prices are well defined in terms of product specification, delivery, and other conditions defined in the contract. 
One issue that arises in this regard is the procedure to be used in estimating spot prices. Gibson and Schwartz (1990) considered the first futures contract (herein termed F1, which is a 1-month delivery contract) as a proxy for spot prices. In their work, there is a second variable that is also un-observable: the convenience yield. The convenience yield was, therefore, estimated based on the relation between successive futures contracts. Pindyck (2004) extrapolated the F1 price to the present date, based on the price relation between the first and second futures contracts (F1 and F2) and their respective maturities. Here, we use the Schwartz and Smith (2000) model, also known as the two-factor model. They consider that the logarithm of the spot price $\mathrm{S}_{\mathrm{t}}$ is the sum of two factors: short-term variations $\left(\chi_{t}\right)$ and equilibrium prices $\left(\xi_{t}\right)$. These factors (or state variables) should be estimated based on observations of futures prices. Once they are estimated, the spot price is obtained automatically. The authors used their model to describe the behavior of the oil price. Subsequent works applied this model to other commodities: Manoliu and Tompaidis (2000) for natural gas and Sørensen (2002) for agricultural commodities. The model considers that $\chi_{t}$ evolves following an Ornstein-Uhlenbeck process, and that $\xi_{t}$ follows a geometric Brownian motion. The model is expressed as follows:

$$
\begin{aligned}
& \ln \left(\mathrm{S}_{\mathrm{t}}\right)=\chi_{\mathrm{t}}+\xi_{\mathrm{t}} \\
& \mathrm{d} \chi_{\mathrm{t}}=-\mathrm{k}_{\chi} \chi_{\mathrm{t}} \mathrm{dt}+\sigma_{\chi} \mathrm{dW}_{\chi \mathrm{t}} \\
& \mathrm{d} \xi_{\mathrm{t}}=\mu_{\xi} \mathrm{dt}+\sigma_{\xi} \mathrm{dW}_{\xi \mathrm{t}} \\
& \rho d \mathrm{t}=\mathrm{dW}_{\chi \mathrm{t}} \mathrm{dW}_{\xi \mathrm{t}}
\end{aligned}
$$

where $\mathrm{k}_{\chi}$ is the speed of reversion, $\sigma_{\chi}$ is the diffusion parameter of the $\chi_{\mathrm{t}}$ process, $\mathrm{dW} \mathrm{Wt}_{\mathrm{t}}$ is the increment of the standard Wiener process, $\mu_{\xi}$ is the drift of $\xi_{t}, \sigma_{\xi}$ is the diffusion parameter, $\mathrm{dW}_{\xi \mathrm{t}}$ is the increment of the standard Wiener process for $\xi_{t}$, and $\rho$ represents the correlation between the state variables.

Equation (01) describes the model according to the "true" probability measure. To derive the future prices equation, the model must be expressed in the equivalent martingale measure. This derivation can be seen in the Schwartz and Smith (2000) article or can be undertaken using the Duffie and Kan (1996) transform; this is also described in Duffie et al. (2000), as the above processes are affine. In any regard, the following futures price equation is obtained:

$$
\ln \left(\mathrm{F}_{\tau, \mathrm{t}}\right)=\mathrm{e}^{-\mathrm{k}_{\chi}(\tau-\mathrm{t})} \chi_{\mathrm{t}}+\xi_{\mathrm{t}}+\mathrm{A}(\tau-\mathrm{t})
$$

where $F_{\tau, t}$ is the future price in $t$ with maturity in $\tau$ and $A(\tau-t)$ is given by

$$
\mathrm{A}(\tau-\mathrm{t})=\left(\mu_{\xi}^{*}(\tau-\mathrm{t})-\frac{\lambda_{\chi}}{\mathrm{k}_{\chi}}\left(1-\mathrm{e}^{-\mathrm{k}_{\chi}(\tau-\mathrm{t})}\right)+\frac{\sigma_{\chi}^{2}}{4 \mathrm{k}_{\chi}}\left(1-\mathrm{e}^{-2 \mathrm{k}_{\chi}(\tau-\mathrm{t})}\right)+\frac{\rho \sigma_{\chi} \sigma_{\xi}}{\mathrm{k}_{\chi}}\left(1-\mathrm{e}^{-\mathrm{k}_{\chi}(\tau-\mathrm{t})}\right)+\frac{1}{2} \sigma_{\xi}^{2}(\tau-\mathrm{t})\right)
$$

Where, $\mu_{\xi}^{*}=\mu_{\xi}-\lambda_{\xi}$ and $\lambda_{\chi}$ and $\lambda_{\xi}$ are the market prices of risk for $\chi$ and $\xi$, respectively.

In Equation (2), the logarithm of the future price is linear in both state variables. The state variables are Gaussian. Under these conditions, the model can be estimated using the Kalman filter. The hyperparameters $\left(\mu_{\xi}^{*}, \lambda_{\chi}, \mathrm{k}_{\chi}, \sigma_{\chi}, \sigma_{\xi}, \rho\right)$ are estimated maximizing the likelihood of the prediction error, and the state variables $\left(\chi_{t}\right.$ and $\left.\xi_{t}\right)$ are estimated for each time. See Harvey (1989) and Durbin and Koopman (2002), among others, the details of the Kalman filter.

We proceed as above, using daily closing prices for five futures contracts from NYMEX. The five historical future prices cover the period from 01/02/1990 to 03/08/2006, forming a panel with 4053 observations for each contract. These prices refer to contract maturing after periods of 1, 5, 9, 13, and 17 months (F1, F5, F9, F13, and F17, respectively). Table 1 lists the statistics of the observed price series. We then estimated the state variables $(\chi, \xi)$ and the hyperparameters. The spot price is given by $S_{t}=\exp \left(\chi_{t}+\xi_{t}\right)$ and is shown in Figure 1 with the price of the first contract, F1. The volatility is then estimated based on the $S_{t}$ series.

\subsection{Stylized facts in the $S_{t}$ series}


As the spot-price series $S_{t}$ was estimated rather than observed, we now seek to verify whether the main stylized facts of the financial time series observed in the markets are also present in the $S_{t}$ series.

\begin{tabular}{lrrrrr}
\hline \multicolumn{5}{c}{ Table 01:Descriptive statistics of future prices collected from NYMEX (US\$/bbl) } \\
\hline Contracts & F1 & F5 & F9 & F13 & F17 \\
\hline Mean & 25.94 & 25.34 & 24.75 & 24.33 & 24.03 \\
Median & 21.68 & 21.06 & 20.64 & 20.35 & 20.22 \\
Std Deviation & 11.52 & 11.57 & 11.38 & 11.17 & 10.96 \\
Maximum & 69.81 & 70.54 & 70.77 & 70.82 & 70.58 \\
Minimum & 10.72 & 11.88 & 12.45 & 12.92 & 13.33 \\
Kurtosis & 5.83 & 7.16 & 8.13 & 8.81 & 9.30 \\
\hline
\end{tabular}

The log-return series was calculated as $r_{t}=\log \left(\frac{S_{t}}{S_{t-1}}\right)$ and includes 4052 observations. Figure 2 shows the return for the entire period, while Table 2 provides the key statistics of this series.

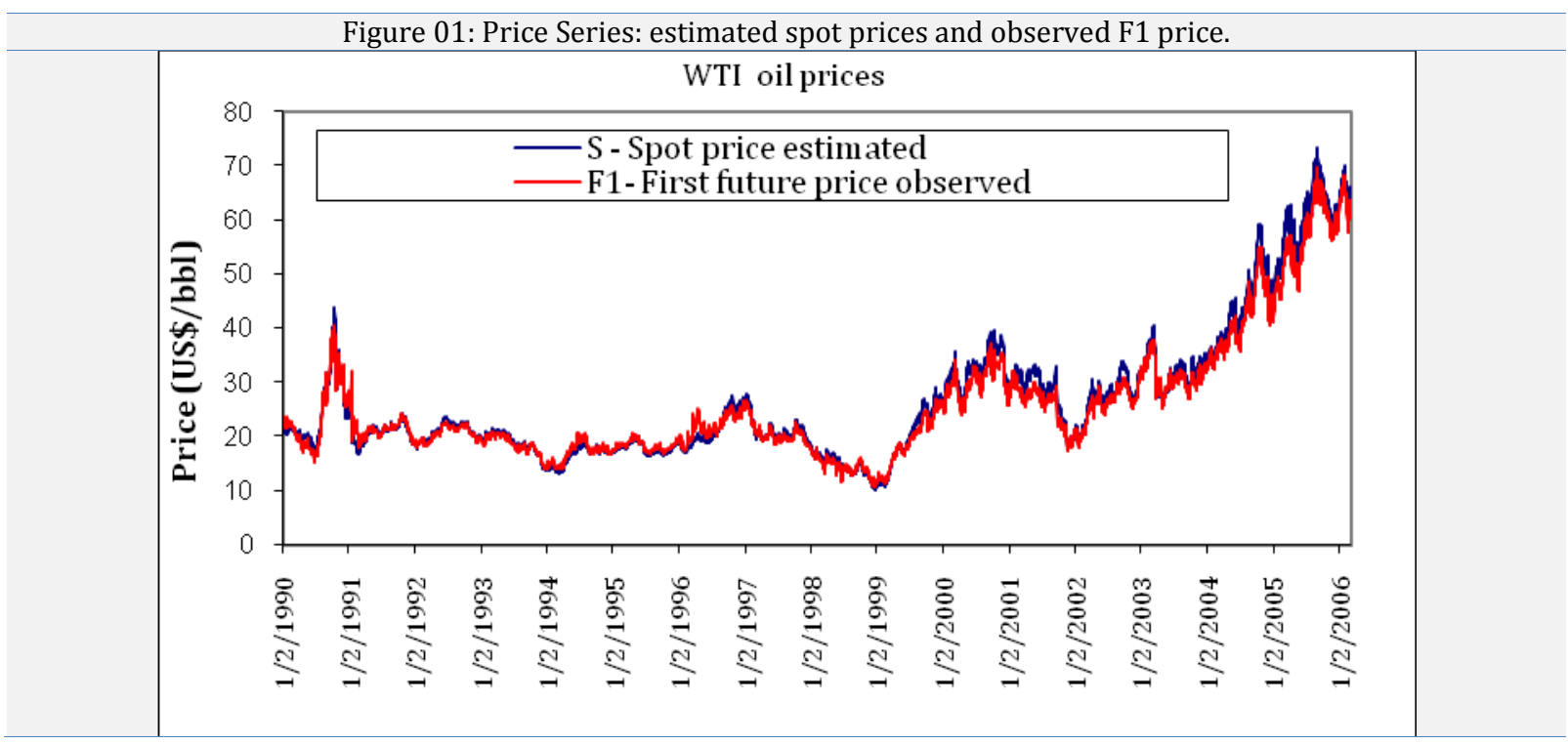

Figure 02 reveals periods of extreme volatility, as in August 1990 when Iraq invaded Kuwait and oil prices climbed due to high stock formation. In January 1991, the US attacked Iraq and began to use its strategic reserve of approximately 33.75 million barrels of oil; prices dropped to around US\$10/bbl. Another period of high volatility occurred in March 1998 when prices were falling, and OPEC decided to cut daily production by 1.25 million barrels. On 09/24/2001, after the terrorist attacks, oil prices fell to their lowest levels in 2 years as agents feared a period of the global recession. On that day, NYMEX prices dropped US\$3.96/bbl to US $\$ 22.01 / \mathrm{bbl}$.

\begin{tabular}{lllllll}
\hline \multicolumn{7}{c}{ Table 02: Statistics of the return series $r_{t}$} \\
\hline & Obs. & Mean & Maximum & Minimum & Std Dev & Kurtosis \\
\hline$r_{t}=\log S_{t}-\log S_{t-1}$ & 4052 & 0.000258 & 0.129817 & -0.318811 & 0.021128 & 18.94717 \\
\hline
\end{tabular}

The series exhibits an excess of kurtosis (see Table 2). The auto-correlation function (ACF) and Ljung and Box statistics reject the null hypothesis that there is no correlation. We used the ADF (Augmented Dickey-Fuller) test to verify the stationarity of $\left\{r_{t}\right\}$. The result rejects the null hypothesis of a unit root in favor of stationarity. The ADF test statistic is -61.4351 , and MacKinnon one-side p-value is 0.0001 . 


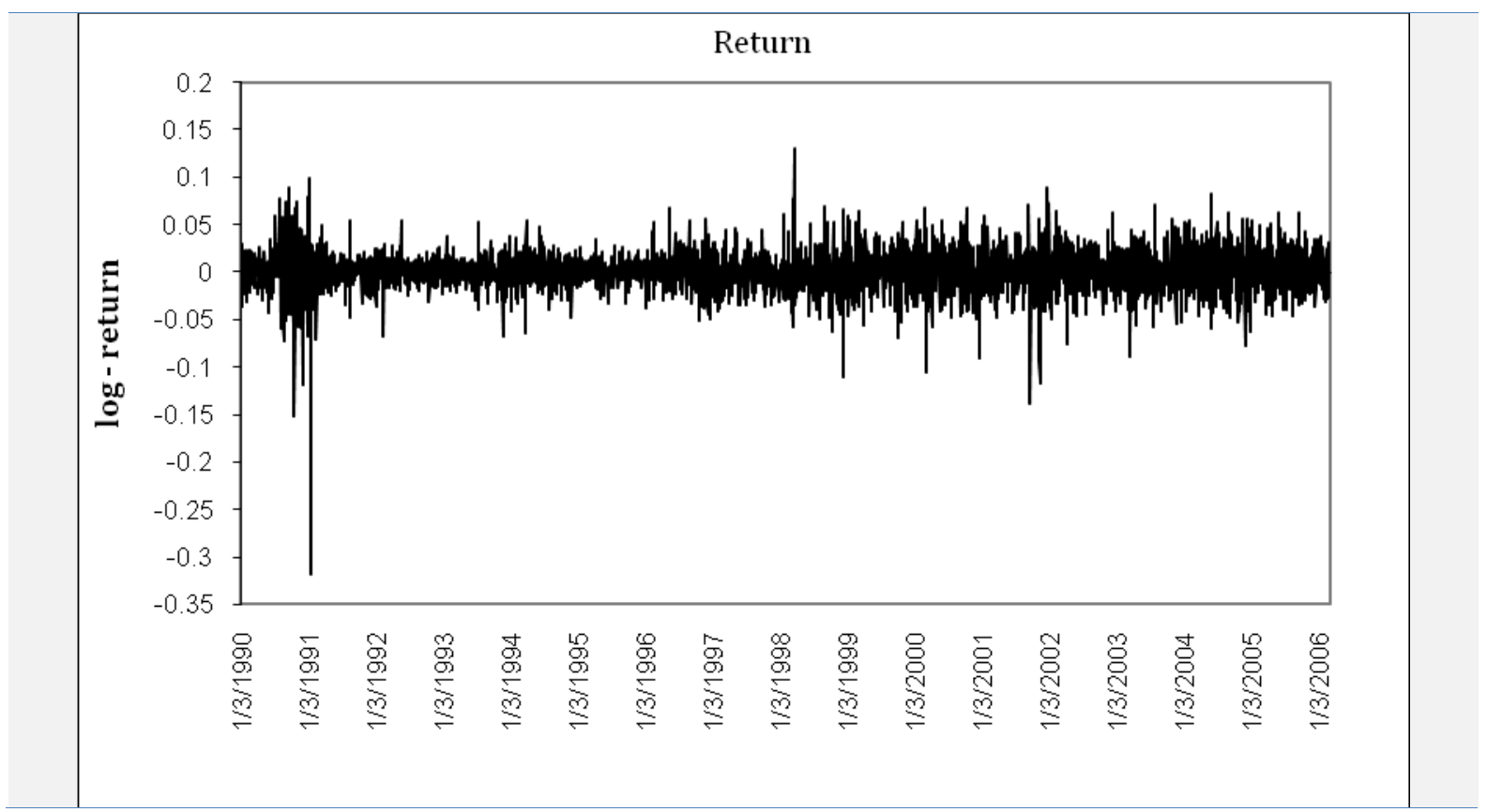

The BDS (Brock et al. (1987)) rejects the null hypothesis of independence in ten-dimensional space (the BDS test statistic in $10^{\text {th }}$ dimension space is 0.013132 with std error 0.001333 ). Therefore, we adjusted an AR (2) according to the Akaike criteria. The ACF of the residuals after this adjustment shows that one accepts the null hypothesis, which means that the correlation coefficients are insignificant at the $5 \%$ level. The test of the squared residuals shows a non-linear dependence. The ARCH-LM test rejects the null hypothesis that there is no ARCH effect (the ARCH-LM statistic, including 10 lags, is 155.0287 and the corresponding p-value of chi-square with $10 \mathrm{df}$ is zero).

On the basis of the tests described above, we were able to verify that the distribution of returns is not Normal: it can be characterized as leptokurtic. Furthermore, the linear dependence was removed via an AR process. We verified the existence of non-linear dependence. This non-linear dependence can be expressed in the mean, in the variance, or in both. We used the Hsieh (1989) test to verify the type of non-linear dependence. The null hypothesis is that the non-linear dependence is in the variance while the alternative hypothesis is that it is in the mean. One accepts that the non-linear dependence is in variance (the details of this test is available upon request).

Given the above conditions, the variance is modeled using a GARCH process; however, the basic GARCH model does not capture the asymmetries of shocks. Another stylized fact present in the financial time-series is the asymmetric or leverage effect. This means that the negative shocks (bad news) have a greater impact on the variance than positive shocks (good news). This phenomenon was first described by Black (1976), who identified it from an analysis of variations in debt to equity; consequently, it was termed the leverage effect. When the equity (stocks) of the firm falls, the ratio of debt to equity increases and also the leverage, leading to an increase in the volatility of the stock. Extended GARCH models, known as non-linear GARCH models, have been developed in an attempt to capture this effect. Engle and Ng (1993) presented tests to verify the asymmetric effects. The authors used the SB (Sign Bias); NSB (Negative Size Bias), PSB (Positive Size Bias), and GT (General Test) tests. The null hypothesis that there is no asymmetry was verified by the SB test; nonetheless, the NSB, PSB, and GT tests reject the null hypothesis, suggesting that asymmetry is present. However, the power of these tests is not great (see Franses and van Dijk (2000)). Because these tests were not conclusive we also used non-linear GARCH model.

In summary, the stylized facts observed in the financial time-series are also observed in the spot-price series estimated in the previous section. The next section analyzes volatility in this series.

\subsection{Conditional volatility models}

The return series, as mentioned above, encompasses the period from 01/02/90 to 03/08/06 and contains 4052 "observations;" it is termed Period 1. Other sub-periods are also analyzed. Period 2 is from 12/10/98 to 09/22/03. The beginning of this period marks the time when oil prices were at their lowest levels (US\$ $10.72 / \mathrm{bbl}$ for F1 contract) while the end of the period in September 2003 marks the end of the cycle, when prices returned to US\$ $30 / \mathrm{bbl}$. Following this, prices dropped below US\$20/bbl once more before returning to US\$ $30 / \mathrm{bbl}$. Period 3 begins on $09 / 23 / 03$ and continues until 03/08/06 (the end of the observed series). In this period, oil prices escalated as never before, reaching US $\$ 70 / \mathrm{bbl}$ before dropping slightly but remaining in the range from US $\$ 60 / \mathrm{bbl}$ to US\$ 70/bbl. Period 4 is the last sub-period; it begins on 10/05/04 and continues until the end of the observed 
series on $03 / 08 / 06$. The beginning of this period marks the time when prices first broke through US\$ $50 / \mathrm{bbl}$ before retreating to an ascendant trajectory.

Periods 1 and 2 were analyzed using both a classical (linear) GARCH model and a non-linear (or asymmetric) model. For Periods 3 and 4, we used the linear GARCH model. Zakoian (1994) and Glosten et al. (1993) independently proposed the TARCH (Threshold GARCH) model to capture the asymmetry property of shocks in the variance. There is also the EGARCH (exponential GARCH) model proposed by Nelson (1991) that captures the asymmetric effect. Engle and Ng (1993) compared TARCH and EGARCH; Hentschel (1995) presents a survey containing the relations in linear GARCH and non-linear GARCH models. Among these linear and non-linear GARCH models, we selected the TARCH model based on the information criteria. We also use the classical GARCH model since the asymmetric tests were not conclusive. Table 3 summarizes the different periods and the selected models.

\begin{tabular}{lllll}
\hline \multicolumn{4}{c}{ Table 03: Summary of analyzed periods } \\
\hline & Beginning & End & Observations & Model \\
\hline Period 1 & $01 / 02 / 1990$ & $03 / 08 / 2006$ & 4052 & TARCH/GARCH \\
Period 2 & $12 / 10 / 1998$ & $09 / 22 / 2003$ & 1193 & TARCH/GARCH \\
Period 3 & $09 / 23 / 2003$ & $03 / 08 / 2006$ & 713 & GARCH \\
Period 4 & $10 / 05 / 2004$ & $03 / 08 / 2006$ & 356 & GARCH \\
\hline
\end{tabular}

The TARCH $(p, q)$ model is given by:

$$
h_{t}=\omega+\sum_{i=1}^{q} \alpha_{i} \varepsilon_{t-i}^{2}+\sum_{j=1}^{p} \beta_{j} h_{t-j}+\sum_{k=1}^{s} \gamma_{k} \varepsilon_{t-k}^{2} I_{t-k}^{-}
$$

Where, the first three terms of the right-hand side have the same meaning as those in the classical GARCH model. The last term models the asymmetry via the indicator function $I_{t}^{-}$and $s$ is the number of lags. If there is bad news, $\varepsilon_{t}<0$ and $I_{t}^{-}=1$; for good news, $\varepsilon_{t}>0$ and $I_{t}^{-}=0$.

Period 1 follows the specification

$$
r_{t}=\varphi_{1} r_{t-1}+\varphi_{2} r_{t-2}+\varepsilon_{t}
$$

where $\varepsilon_{t}=h_{t}^{1 / 2} v_{t}$ e $v_{t} \sim$ Student's t distribution with degrees of freedom to be estimated. The variance is given by

$$
h_{t}=\omega+\alpha \varepsilon_{t-1}^{2}+\beta h_{t-1}+\gamma_{1} \varepsilon_{t-1}^{2} I_{t-1}^{-}+\gamma_{2} \varepsilon_{t-2}^{2} I_{t-2}^{-}
$$

The positive shocks have an impact of $\alpha$ on variance, which is $h_{t}=A+\alpha \varepsilon_{t-1}^{2}$ where $A=\omega+\beta h_{t-1}$. Negative shocks of the same size in $t-1$ and $t-2$ have an impact of $\alpha+\gamma_{1}+\gamma_{2}$, and the variance is given by $h_{t}=\mathrm{A}+\left(\alpha+\gamma_{1}+\gamma_{2}\right) \varepsilon_{t-1}^{2}$. If $\gamma_{1}+\gamma_{2} \neq 0$, then the impact of bad news is asymmetric. The persistence is defined by $\eta=\alpha+\frac{1}{2}\left(\gamma_{1}+\gamma_{2}\right)+\beta$. A persistence of less than one means that the conditional volatility is of the mean-reverting type and that the shocks are transitory. The half-life for $\eta<1$ is the time required for the conditional volatility to return to the unconditional mean: $-\frac{\ln 2}{\ln \eta}$. We followed Akaike criteria in defining the number of terms in (5). Period 1 was also estimated using GARCH $(1,1)$ which selection was based on Akaike criteria, and using the Student's t distribution. Period 2 has the same specification as that in Equations (4) and (5),

\begin{tabular}{|c|c|c|c|c|c|}
\hline \multicolumn{6}{|c|}{ Table 04: Summary of the results of the estimation } \\
\hline & & Period 1 & Period 2 & Period 3 & Period 4 \\
\hline GARCH & $\omega$ & $\begin{array}{l}2.09 \times 10^{-6 *} \\
(2.09)\end{array}$ & $\begin{array}{l}1.21 \times 10^{-5} \\
(1.93)\end{array}$ & $\begin{array}{l}1.54 \times 10^{-5} \\
(0.60)\end{array}$ & $\begin{array}{l}2.26 \times 10^{-5} \\
(0.61)\end{array}$ \\
\hline & $\alpha$ & $\begin{array}{l}0.051025^{*} \\
(7.72)\end{array}$ & $\begin{array}{l}0.028899^{*} \\
(2.71)\end{array}$ & $\begin{array}{l}0.015757 \\
(1.06)\end{array}$ & $\begin{array}{l}0.028901 \\
(0.29)\end{array}$ \\
\hline & $\beta$ & $\begin{array}{l}0.946272^{*} \\
(141.52)\end{array}$ & $\begin{array}{l}0.946701^{*} \\
(49.1)\end{array}$ & $\begin{array}{l}0.952281^{*} \\
(14.94)\end{array}$ & $\begin{array}{l}0.922934^{*} \\
(9.48)\end{array}$ \\
\hline & $\alpha+\beta$ & 0.997297 & 0.9756 & 0.968088 & 0.951835 \\
\hline & DW & 1.942053 & 1.96786 & 2.004895 & 1.983316 \\
\hline & df & $\begin{array}{l}5.715820^{*} \\
(11.34)\end{array}$ & $\begin{array}{l}7.626279^{*} \\
(5.10)\end{array}$ & & \\
\hline
\end{tabular}
and was also analyzed using GARCH $(1,1)$ under the condition described above. Periods 3 and 4 were specified with GARCH $(1,1)$ with GED (Generalized Error Distribution). Table 4 lists the results of the estimation process. 


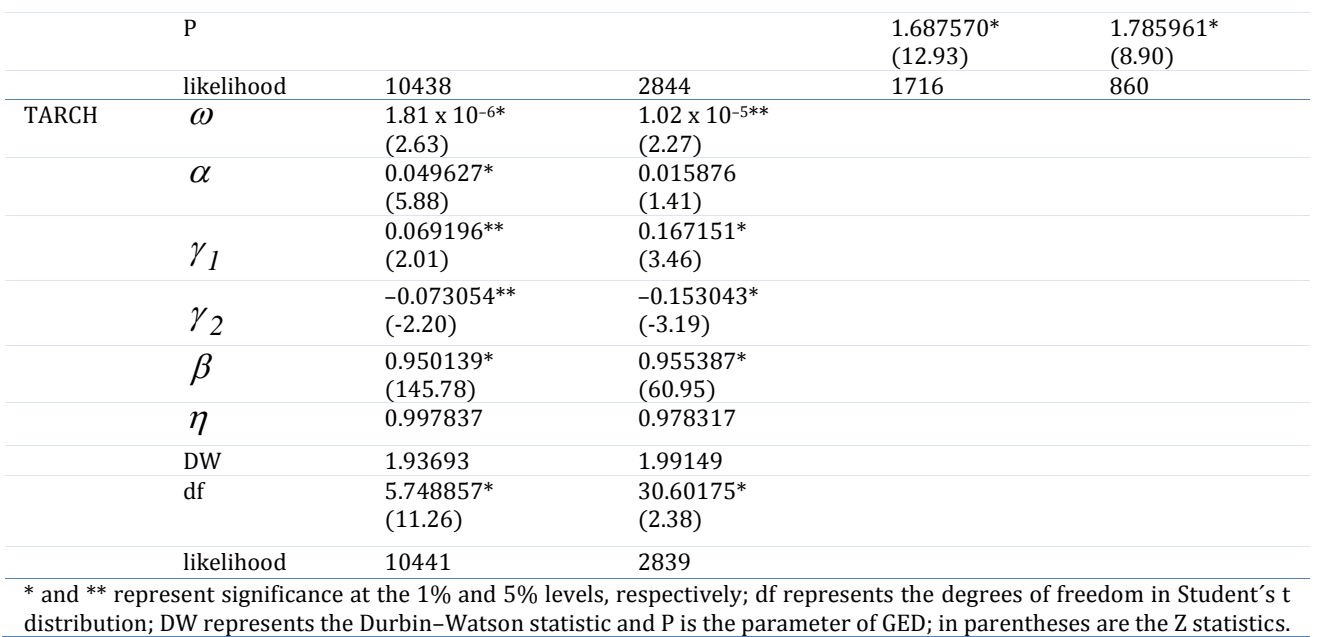

The results show that the parameters related to the asymmetry are significant at the $5 \%$ level for the entire series and at the $1 \%$ level for the second period. For the last two periods, the GARCH $(1,1)$ model had the best adjustment. The persistence, which is always less than one, demonstrates that the shocks are transitory. In Period 1, the half-life in the TARCH and GARCH models are similar, being approximately 1 year. In Period 2, the half-life for both models is approximately 6 weeks. In Periods 3 and 4, the half-lives are 4 and 3 weeks, respectively. After undertaking estimates using each model, we analyzed the residuals. The ACF and the Ljung and Box statistics for the residual and for the squared residuals accept the null hypothesis that there is no correlation. The ARCH-LM test shows that there is no remaining ARCH effect.

Figure 3 shows the behavior of the GARCH and TARCH models for Period 1 as well as the return series. The volatility on the right-hand axis is annualized. Comparing the return series and volatilities, it is apparent that periods of significant variations in the return series are related to high volatility in the two models. The volatility in the TARCH model is greater than that for GARCH for points where there is a negative shock. This is precisely the difference between the two models; the effect of bad news is clear. Following a period of high volatility resulting from bad news, subsequent volatility remains high.

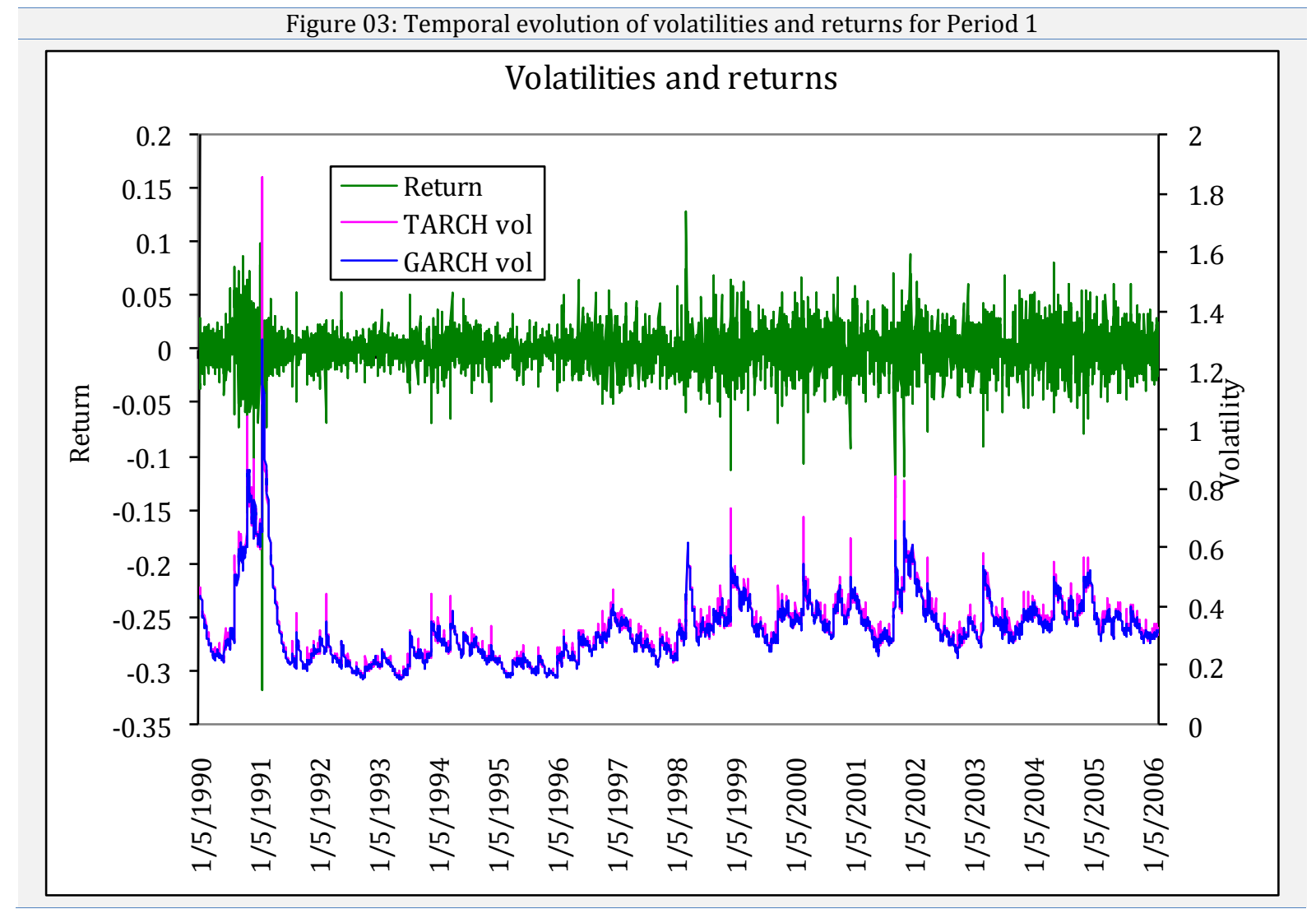

Table 5 provides a summary of the statistics in which figures are annualized volatilities. It is worth noting that, in Period 1, both the GARCH and TARCH models predict volatilities that are close, around 32\% per year. In Period 2, 
when oil prices were initially very low and subsequently increased, the average volatility was higher (36\% per year), and the two models show similar results. In Period 3, when prices rose sharply to US\$ 70/bbl, there was no increase in volatility. If we compare Periods 3 and 2, volatility was lower in Period 3, at 35\% per year. In Period 4, when oil prices were above US\$ $50 / \mathrm{bbl}$, the average volatility was $34 \%$ per year; that is, without any significant change from the previous period. Note that, in recent years when oil prices have fluctuated at high levels, the volatility has not changed; in fact, there was a small reduction. The persistence of shocks decreased in recent years, indicating that recent shocks are even more transitory. Also note that, in Period 2, when prices increased from their lowest levels, volatility and persistence were higher than in Periods 3 and 4.

\begin{tabular}{llllllll}
\hline \multicolumn{7}{c}{ Table 05: Statistics of the estimated volatility series } \\
\hline \multirow{2}{*}{ Period 1 } & Mean & Std Dev & Minimum & Maximum & Skewness & Kurtosis \\
& GARCH & 0.320 & 0.120 & 0.148 & 1.309 & 2.267 & 13.227 \\
Period 2 & TARCH & 0.319 & 0.120 & 0.146 & 1.856 & 2.400 & 16.599 \\
& GARCH & 0.364 & 0.057 & 0.281 & 0.647 & 1.616 & 6.282 \\
Period 3 & TARCH & 0.359 & 0.069 & 0.277 & 0.985 & 2.996 & 19.244 \\
Period 4 & GARCH & 0.348 & 0.017 & 0.323 & 0.411 & 1.256 & 4.475 \\
\hline
\end{tabular}

Table 6 summarizes the average volatility using both models for the entire series, highlighting the last 12 and 24 months.

\begin{tabular}{lcc}
\hline \multicolumn{3}{c}{ Table 06: Average volatility for last 12 and 24 months using the entire series } \\
\hline & TARCH & GARCH \\
\hline January 2004 to March 2006 & 0.3608 & 0.3598 \\
January 2005 to March 2006 & 0.3400 & 0.3388 \\
\hline
\end{tabular}

In the last 24 months, the average volatility was $36 \%$ per year. In the last year, the average volatility was $34 \%$ per year, in a scenario where prices remained above US $\$ 60 / \mathrm{bbl}$ and the volumes negotiated (in terms of the number of contracts) were the highest ever negotiated in the oil futures market. These results are clear from Figure 3 where one can observe greater volatilities before 2004 .

\subsection{Conclusions}

This article analyzed the behavior of volatility of oil spot prices. First, we estimated the spot prices using the Schwartz and Smith (2000) two-factor model. This procedure provides more reliable information than what is usual done in the literature that uses only the first future contract or the price information coming from the trading on the physical market. Once the spot prices had been obtained, we verified the presence of the main stylized facts of the financial time-series. It was not possible to characterize precisely the asymmetric effect of shocks. The return series of spot prices was analyzed over different time periods, using both the GARCH and TARCH models.

The GARCH model, based on data from 1990 to 2006, showed that volatility in the high price regime is not different from the volatility in the low price periods. It is clear that the presence of agents such as Hedge Funds has not led to an increase in the volatility of oil prices. The shocks behaved as transitory and the persistence in the high price regime decreased. The TARCH model showed similar results to those of the GARCH model, although the asymmetric parameters are significant. The half-life in both models was close to 1 year for the entire period. For sub-periods, the half-life was between 3 and 6 weeks. It is worth noting that during the period when prices changed abruptly to the current high levels, the volatility did not change significantly, and the half-life was 4 weeks. All of these facts lead us to the same conclusion as that of Pindyck (2004): that shocks affecting volatility have consequences for the pricing of financial derivatives but are inconsequential for investment decisions in real assets (e.g., the maturity of an oil project lies beyond the shock effect). This research will be extended in the future to deal with the stochastic volatility and long-memory models. The comparison of different modeling results will improve our understanding of volatility in oil prices in this new era of high prices.

\section{References}

Baillie, R. T., Myers, R. J., 1991. Bivariate GARCH estimation of the optimal commodity futures hedge. Journal of Applied Econometrics, 6: 109-124. http://dx.doi.org/10.1002/jae.3950060202

Barsky, R., Kilian, L., 2004. Oil and the macroeconomy since the 1970s.Working paper 10855, NBER, http://www.nber.org/papers/w10855.

Black, F., 1976. The pricing of commodity contracts. Journal of Financial Economics, 3, 167-179. http://dx.doi.org/10.1016/0304-405X(76)90024-6 
Brock, W., Dechert, W. D., Scheinkman, J., 1987. A test for independence based on the correlation dimension. Working paper, Department of Economics, University of Wisconsin, Madison, University of Houston, and University of Chicago.

Duffie, D., Kan, R., 1996. A yield-factor model of interest rates. Mathematical Finance, 6(4): 379-406. http://dx.doi.org/10.1111/j.1467-9965.1996.tb00123.x

Duffie, D., Pan, J., Singleton, K. J., 2000. Transformation analysis and asset pricing for affine jump-diffusions, Econometrica, 68(6): 1343-1376. http://dx.doi.org/10.1111/1468-0262.00164

Durbin, J., Koopman, S. J., 2002. Time Series Analysis by State Space Methods. Oxford Statistical Science Series, 24. Oxford University Press, Oxford.

Engle, R., Ng, V., 1993. Measuring and testing the impact of news on volatility. Journal of Finance, 48: 1749-1778. http://dx.doi.org/10.1111/j.1540-6261.1993.tb05127.x

Franses, P. H., van Dijk, D., 2000. Non-linear Time Series Models in Empirical Finance. Cambridge University Press, Cambridge. http://dx.doi.org/10.1017/CB09780511754067

Gibson, R., Schwartz, E. S., 1990. Stochastic convenience yield and the pricing of oil contingent claims. The Journal of Finance, 45(3): 959-976. http://dx.doi.org/10.1111/j.1540-6261.1990.tb05114.x

Glosten, L. R., Jagannathan, R., Runkle, D., 1993. On the relation between the expected value and the volatility of the nominal excess return on stocks. The Journal of Finance, 48: 1779-1801. http://dx.doi.org/10.1111/j.15406261.1993.tb05128.x

Hadsell, L., Marathe, A., Shawky, A., 2004. Estimating the volatility of wholesale electricity spot prices in the US. The Energy Journal, 25(4): 23-40. http://dx.doi.org/10.5547/ISSN0195-6574-EJ-Vol25-No4-2

Harvey, A. C., 1989. Forecasting, Structural Time Series Models and the Kalman Filter. Cambridge University Press, Cambridge.

Hentschel, L., 1995. All in the family nesting symmetric and asymmetric GARCH models. Journal of Financial Economics, 39: 71-104. http://dx.doi.org/10.1016/0304-405X(94)00821-H

Horan, S. M., Peterson, J. H., Mahar, J.,2004. Implied volatility of oil futures options surrounding OPEC meetings. The Energy Journal, 25(3): 103-125. http://dx.doi.org/10.5547/ISSN0195-6574-EJ-Vol25-No3-6

Hsieh, D. A., 1989. Testing for nonliner dependence in daily foreign exchange rates. Journal of Business, 62(3): 339368. http://dx.doi.org/10.1086/296466

Lautier, D., Riva, F., 2004. Volatility in the American crude oil futures market. Working paper, University Paris Dauphine.

Manoliu, M., Tompaidis, S., 2000. Energy futures prices: Term structure models with Kalman filter estimation. Working paper, University of Texas, Austin.

$\mathrm{Mu}, \mathrm{X} ., 2007$. Weather, storage, and natural gas price dynamics: Fundamentals and volatility. Energy Economics, 29(1): 46-63. http://dx.doi.org/10.1016/j.eneco.2006.04.003

Nelson, D. B., 1991. Conditional heteroskedasticity in asset returns: a new approach. Econometrica, 59: 347-370. http://dx.doi.org/10.2307/2938260

Pindyck, R. S., 2004. Volatility in natural gas and oil market. The Journal of Energy and Development, 30(1): 1-19.

Schwartz, E. S., Smith, J. E., 2000. Short term-variations and long-term dynamics in commodity prices. Management Science, 46: 893-911. http://dx.doi.org/10.1287/mnsc.46.7.893.12034

Short term-variations and long-term dynamics in commodity prices: Incorporating a stochastic growth rate, available at http://faculty.fuqua.duke.edu/\%7Ejes9/bio/Linked_Paper_List.htm

Sørensen, C., 2002. Modeling seasonality in agricultural commodity futures. Journal of Futures Markets, $22: 393$ 426. http://dx.doi.org/10.1002/fut.10017

U.S.-EIA, 2002. Derivatives and risk management in the petroleum, natural gas, and electricity industries. Tech. rep., U.S. Energy Information Administration.

Wilson, B., Aggarwal, R., Inclan, C., 1996. Detecting volatility changes across the oil sector. The Journal of Futures Markets, 16(3): 313-330. http://dx.doi.org/10.1002/(SICI)1096-9934(199605)16:3<313::AIDFUT4>3.0.CO;2-M

Zakoian, J. M., 1994. Threshold heteroskedastic models. Journal of Economic Dynamics and Control, 18: 931 -955. http://dx.doi.org/10.1016/0165-1889(94)90039-6 